\title{
WADING INTO WATER
}

\author{
On the shores of memory.
}

BY TODD HONEYCUTT

W

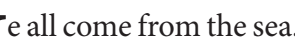

That's what the science books tell us, and what I think of as I walk the beaches near my home, listening to the ocean waves sing their songs against the earth; watching the gulls struggle with each other for scraps of food; collecting odd debris and shells pushed up by the waves.

What I think of as I remember my daughter.

Our last conversation - our last face-to-face conversation occurred almost two years ago. Pearl had called, said she wanted to see me, had something important to say. I asked her to come to my shore house, because the city perplexes me more than it did when I was younger, and the tone of her voice made me think that it would be better on my turf than hers.

We weren't estranged, Pearl and I. After her mother's and my divorce, and her flowering into her own as an adult, we had just, as they say, grown apart. A natural progression of our lives, I guess, as children stand on their own, find their own paths. But I wished things had been different.

Still do.

Pearl came the following weekend, a Saturday morning in September. We bought coffees and walked to the boardwalk, found a bench facing the ocean. People and umbrellas dotted the sand between us and the sea. No cloud in that tranquil sky tempered the brightness of the Sun.

We talked of pleasantries, memories of beach vacations past. Then Pearl cut to the core of the issue.

"I'm going to be uploaded."

"Uploaded?" I said.

I had heard of it, of course, but hadn't paid any attention. Didn't concern me. Not much in the news did. One of the advantages of growing old - nothing seems newsworthy any more.

Almost nothing.

"A friend of a friend has me on a list. It's beyond the experimental stage now. It's safe."

"But you lose..."

"I lose this body, and I gain so much more. It's the new frontier, Dad."

As if it were the Wild West or the Moon base.

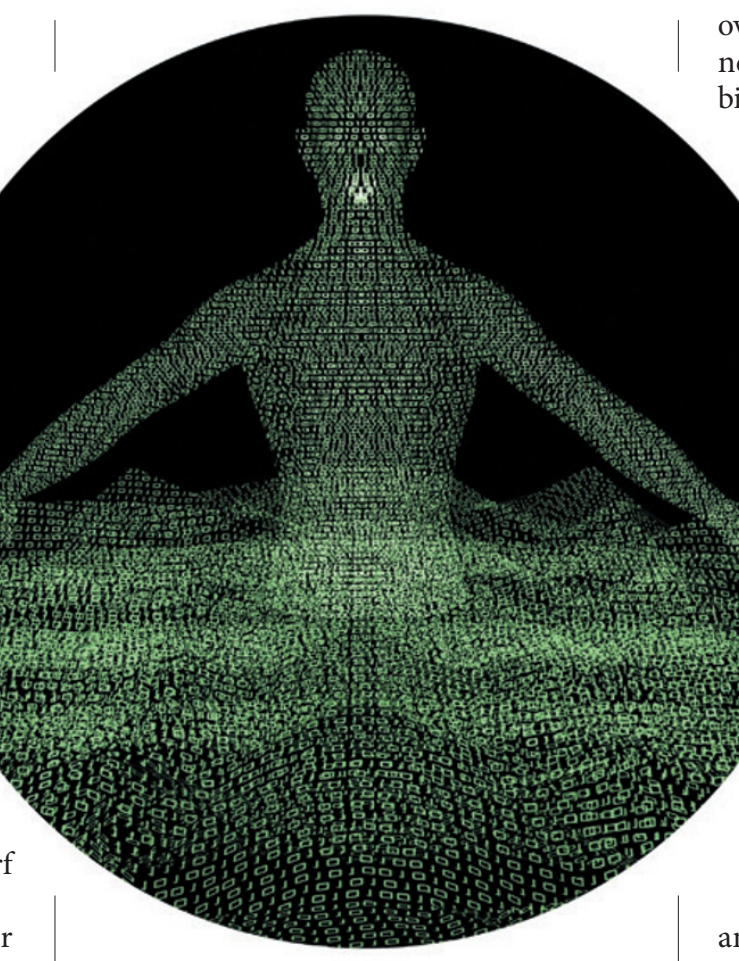

What can a father say to the choices his children make? How many times had my pleas had no effect? Or worse, cornered her to become more firmly entrenched?

When my words had ebbed, Pearl filled the space with information about the procedure. I couldn't hear her words, or what I could hear, I couldn't make sense of. I know more now. How the brain is put in a small vat, bathed in salts and chemicals and solutions. Wired so that its consciousness is free to roam worlds both virtual and real. Entire civilizations rise and fall, fantastic landscapes more strange than any I can imagine have people living, working, achieving, actualizing. Perhaps it is the new frontier, but it's hard for me to understand a world without the taste of food and drink, the feel of sand and water.

Yes, I know more about it now.

"Honey, it seems so permanent, so ..."

"I'll still be around." Pearl touched my arm. "I'll still be me. Just ... in a different form."

I finished my coffee, held the cup against my leg to keep the wind from tossing it along the boardwalk. I looked at Pearl, at the woman she had become. Strong, independ- $\rightarrow$ NATURE.COM

Follow Futures: @NatureFutures f go.nature.com/mtoodm ent. Her stubbornness had matured into assuredness and confidence. She had parleyed her overwhelming curiosity and political astuteness into a career transforming boutique biotech companies into global players.

I was proud of her. I just wished I could have shared her excitement.

"When?"

"Not sure, but soon."

"What about your mother?"

"I haven't told her."

"She'll be heartbroken." Easier to say than that I was heartbroken.

"Some day," she said, "maybe you both will join me."

Some day, her mother would.

"Let's go swimming," I said.

"Swimming?"

I pointed to the ocean.

"I didn't bring a suit."

"I know a store down the road." I pointed behind us.

"Dad, really."

"Please."

She acquiesced.

We waded into the water, my daughter and me, for what would be the last time. It wasn't Pearl at age two, screaming at the monstrosity of the ocean, its vastness. It wasn't the joy of Pearl at nine, excited at each wave, her whole body giggling as she fought and swam and dived. It wasn't the angst of Pearl at 15, the constant churning of, and chattering with, friends. It was Pearl as an adult. The water took us and allowed us to be together in a way we hadn't in years. We floated and body surfed, smiles on our faces as the waves crashed over us and threw us into the sand, the crunch of shells under our feet, the briny taste of the water filling our mouths, and in between, our small talk of city life and beach life and our shared memories of family and each other. Throughout it all, the sounds of the ocean rising and falling, the weight of my heart, rising and falling.

The papers are signed, my name on a list. I focus on the tastes and touches and sounds I encounter, as if they'll be the last I'll know. And each day, I sit on the boardwalk and wonder, as the waves rise and fall, whether I'll feel the same as our last day in the ocean when I next see my daughter.

Todd Honeycutt is a public-health researcher in New Jersey who enjoys thinking about alternatives (and alternatives to alternatives). His stories have appeared in Fiction Vortex. 